\title{
A sustentabilidade como política pública: conceitos e óticas da política ambiental nacional
}

\section{Rodrigo Ramos da Cruz ${ }^{1}$,*, Hugo Marinni Silva Alencar ${ }^{1}$, Hildelayne Ferreira da Silva ${ }^{2}$ e Randerson Ramos da Cruz $^{3}$}

\begin{abstract}
${ }^{1}$ Universidade Federal do Piauí. Programa de Pós-Graduação em Administração Pública. Campus Universitário Ministro Petrônio Portella. Bairro Ininga. Teresina-PI, Brasil (CEP 64049-550). *E-mail: rodrigo.rcruz@hotmail.com.

${ }^{2}$ Universidade Federal do Maranhão. Curso de Graduação em Licenciatura em Ciências Naturais - Química. Campus Grajaú. Av. Aurila Maria Santos Barros de Sousa, 2010. Loteamento Frei Alberto Beretta. Grajaú-MA, Brasil (CEP 65940-000). ${ }^{3}$ Universidade Estadual do Maranhão. Curso de Graduação em Licenciatura em Geografia. Centro Universitário Darcy Ribeiro. Rodovia MA-304, Trecho Canabrava - Povoado Bom Gosto. Tutóia-MA, Brasil (CEP 65580-000).
\end{abstract}

Resumo. 0 presente estudo tem como objetivo revisar conceitos de suma importância para a construção da política ambiental brasileira. Para isto, são expostos alguns conceitos de sustentabilidade, além de definições e características de políticas públicas. Em seguida, é feito um breve resgate histórico da política ambiental brasileira, principalmente em ações e movimentos que influenciaram a política ambiental nacional. Utilizou-se como metodologia a revisão bibliográfica. 0 resgate histórico é necessário para se compreender a política ambiental em três momentos: política ambiental corretiva, preventiva e integradora. A pesquisa permite identificar que, apesar do termo desenvolvimento sustentável ser conhecido desde a conferência de Estocolmo, somente nos anos 1990, com políticas integradoras é que o termo ganhou força e notoriedade, tornando-se um grande foco das políticas públicas ambientais.

Palavras-chave: Política ambiental; Sustentabilidade; política pública.

\begin{abstract}
Sustainability as public policy: Concepts and views of national environmental policy. This study aims to review concepts of paramount importance for the construction of Brazilian environmental policy. For this, some concepts of sustainability are exposed, as well as definitions and characteristics of public policies. Then, a brief historical review of Brazilian environmental policy is made, mainly in actions and movements that influenced the national environmental policy. The literature review was used as a methodology. The historical recovery is necessary to understand the environmental policy in
\end{abstract}

Recebido

$16 / 08 / 2021$

Aceito

$01 / 12 / 2021$

Disponível on line

$05 / 12 / 2021$

Publicado

$31 / 12 / 2021$

Acesso aberto
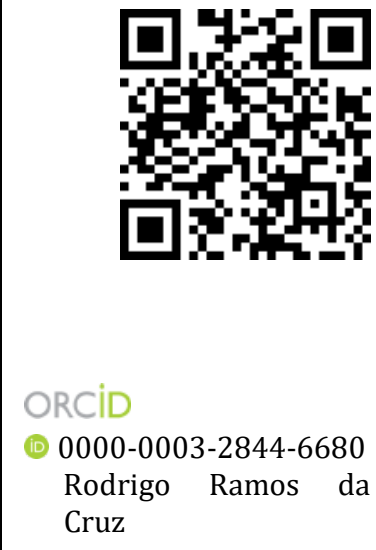

ISSN 2359-1412/RBGAS-2021-0101/2021/8/20/15/1503

Rev. Bras. Gest. Amb. Sustent.

http://revista.ecogestaobrasil.net 
three moments: corrective, preventive and integrative environmental policy. The research allows us to identify that, despite the term sustainable development being known since the Stockholm conference, it was only in the 1990s, with integrative policies that the term gained strength and notoriety, becoming a major focus of environmental public policies.

Keywords: Environmental policy; Sustainability; Public policy.
D 0000-0002-7441-0198

Hugo Marinni Silva Alencar

(D) 0000-0001-7409-786X Hildelayne Ferreira da Silva

D) 0000-0002-7382-7637

Randerson Ramos da Cruz

\section{Introdução}

Considerado instrumento de operacionalização do Estado para conservação do meio ambiente diante dos excessos das relações econômicas, a política ambiental representa as ações que são elaboradas com o objetivo de influenciar a forma de interação dos indivíduos com a natureza. Durante seu ciclo de elaboração, é identificado que a política ambiental sofre influência de fatores técnicos e políticos no processo, características essas, presentes nos processos de formulação de política pública. Pela abrangência de sua área de atuação, a política ambiental acaba por atuar nas mais diversas áreas da sociedade. Na Economia, é visto que a Política Ambiental atua para corrigir as instabilidades que ocorrem nas relações entre o ser humano e o uso de recursos naturais. Nesse sentido, o conceito de sustentabilidade acaba por se tornar o denominador comum dentre as diferentes formas de executar política ambiental, na busca de um desenvolvimento econômico sustentável que busque conciliar os interesses das gerações atuais com a necessidade de conservar o meio ambiente para as gerações futuras.

A Constituição Federal de 1988 assegurou, em seu capítulo VI, art. 225, o direito ao meio ambiente equilibrado como bem de uso comum, atribuindo ao poder público e à população a sua defesa, com o intuito de ser usufruído nessa e nas futuras gerações (Brasil, 1988). Entretanto, a Carta Magna brasileira não é inovadora. Nacionalmente, outras normas já haviam sido ditadas no intuito de conservar o meio ambiente, como, por exemplo o Código de Águas de 1934 (Brasil, 1934) e o Novo Código Florestal de 1965 (Brasil, 1965), que serviram como base para a construção da atual política ambiental brasileira.

O objetivo deste texto é apresentar os conceitos e características da política ambiental no Brasil, mostrando as etapas do processo de sua construção, os agentes envolvidos e os instrumentos utilizados, destacando como ela atua na sociedade brasileira, elencando definições e características da sustentabilidade e da política pública. 0 resgate histórico é necessário para se compreender a política ambiental em três momentos, política ambiental corretiva, preventiva e integradora.

A intenção deste artigo é realizar uma aproximação teórica no intuito de apresentar como a sustentabilidade, a política pública e a política ambiental que atuam na sociedade, enquanto campo do conhecimento científico. E, tendo como metodologia a revisão bibliográfica, esta pesquisa baseou-se em uma busca na literatura por publicações que tratem da conceituação de política ambiental, sustentabilidade e política pública.

\section{Sustentabilidade: o meio ambiente como bem coletivo}

O conceito de sustentabilidade teve origem na silvicultura (Boff, 2017). Da Era Antiga até a Idade Moderna, a madeira foi usada como o principal insumo para a fabricação de imóveis, também como combustível para gerar energia e até na fabricação 
de embarcações. Com sua escassez devido à degradação das florestas, começaram a surgir os debates sobre o seu uso de forma adequada, principalmente em países como Espanha e Portugal, as nações que se destacavam nas explorações navais na épocaSobre isso, Boff (2017, p. 28) diz:

\begin{abstract}
Mas foi na Alemanha, em 1560, na Província da Saxônia, que irrompeu, pela primeira vez, a preocupação pelo uso racional das florestas, de forma que elas pudessem se regenerar e se manter permanentemente. Neste contexto surgiu a palavra alemã Nachhaltigkeit, que significa "sustentabilidade". No entanto foi somente em 1713, de novo na Saxônia, com o Capitão Hans Carl von Carlowitz, que a palavra "sustentabilidade" se transformou num conceito estratégico.
\end{abstract}

Após a Segunda Guerra Mundial, os problemas relacionados à degradação do meio ambiente começaram a ganhar destaque entre as nações (Barbieri, 2020). A preocupação com a poluição de rios, as chuvas ácidas e o aquecimento global mostraram aos países que o modelo econômico acelerado que se difundiu após a guerra estava gerando consequências negativas ao meio ambiente. Ainda nesse raciocínio, Barbieri (2020) destaca que em 1972 foi realizada a Conferência das Nações Unidas sobre o Meio Ambiente Humano, na cidade de Estocolmo, na Suécia. Neste evento, foram definidas as diretrizes para que houvesse uma nova postura com relação à interação entre o ser humano, o meio ambiente e o desenvolvimento. As tratativas desse encontro resultaram na formulação do conceito desenvolvimento sustentável (Barbieri, 2007).

Em 1984, foi criada a Comissão Mundial sobre o Meio Ambiente e Desenvolvimento. Dentre os acontecimentos que ocorreram após a formação dessa comissão, Boff (2017, p. 29) informa sobre a definição de desenvolvimento sustentável, estabelecido como "aquele que atende as necessidades das gerações atuais sem comprometer a capacidade das gerações futuras de atenderem às suas necessidades e aspirações". Este conceito de desenvolvimento sustentável é amplamente utilizado no meio acadêmico. Desta forma, fica estabelecido uma espécie de acordo entre o hoje e amanhã, de forma que os indivíduos devem estabelecer suas relações de consumo de maneira a preserva o meio ambiente.

É importante destacar também o conceito de meio ambiente. Existem diversas descrições, seja do ponto de vista legal, seja do ponto de vista acadêmico. De acordo com a Lei no 6.938/1981 (Brasil, 1981), que estabeleceu a Política Nacional do Meio Ambiente, entende-se meio ambiente como "o conjunto de condições, leis, influências e interações de ordem física, química e biológica, que permite, abriga e rege a vida em todas as suas formas" (Brasil, 1981).

Os níveis de consumo realizados hoje em dia têm gerados os impactos negativos no meio ambiente, gerando uma necessidade de reorientação da forma de consumir dos indivíduos (Liczbinski, 2021). Assim, consumo e meio ambiente possuem uma relação intrínseca, pois os insumos utilizados para a criação de bens e serviços que são consumidos pelas pessoas são retirados da natureza. 0 padrão de consumo elevado está associado à busca do lucro e o estímulo elevado de produção, caraterísticas essas inerentes do sistema capitalista. Para auxiliar na proteção dos recursos disponíveis na natureza, deve haver um estímulo a redução da forma de consumo. A atividade produtiva deve ser realizada de forma a respeitar os limites da natureza, para os insumos que existem atualmente também estejam disponíveis amanhã. Segundo Liczbinski (2021), essa deve ser a primeira meta a ser perseguida para que seja possível um equilíbrio entre meio ambiente, economia e as relações sociais.

Para Boff (2017), a inação do ser humano com relação à necessidade de reorientar seu modo de se relacionar com o meio ambiente é o pior erro que ele pode cometer. Sobre isso, ele comenta (Boff, 2017, p. 8): 
As transformações necessárias devem apontar para um outro paradigma de relação para com a Terra e a natureza, bem como para a invenção de modos de produção e consumo mais benignos. Isso implica inaugurar um novo patamar de civilização, mais amante da vida, mais ecoamigável e mais respeitoso dos ritmos, das capacidades e dos limites da natureza. Não dispomos de muito tempo para agir nem de muita sabedoria e vontade de articulação entre todos para enfrentar o risco comum.

Na busca por um desenvolvimento econômico equilibrado, e tendo o Estado como principal regulador de uma nação, vários países começaram a implementar normas e projetos afim de garantir um equilíbrio entre as relações econômicas e a utilização de recursos naturais. Diretrizes para alteração nos padrões de consumo, bem como regular a exploração ambiental tornaram-se cada vez mais necessárias. A temática ainda era nova, e havia espaço para discussão. Fazia-se então necessário criar agendas para discutir o problema e buscar soluções, e o principal mecanismo para realizar tal feito, seria através das políticas públicas.

\section{A política pública e suas características}

A política pública como foco de pesquisa teve sua origem os Estados Unidos (Souza, 2018). Ela decorre da decisão do Governo de fazer ou não, de forma que seja elaborado através de estudo científico e analisados por pesquisadores. No início de sua utilização como ciência, era atribuído um caráter predominantemente técnico ao estudo da Política Pública. Com o tempo, a utilização de métodos científicos na análise das etapas do processo de elaboração da Política Pública ganha uma maior proporção, passando a identificar que o ciclo era constituído por um jogo político envolvendo atores e instituições (Souza, 2018).

A política pública é uma orientação formada para solucionar um problema de natureza pública. Segundo Secchi $(2013$, p. 3) "a razão para o estabelecimento de uma política pública é o tratamento ou a resolução de um problema entendido como coletivamente relevante". Para Lima e D'Ascenzi (2018) as políticas públicas têm como objetivo viabilizar alterações na sociedade, percebendo a existência de um problema e exigindo a formulação de uma reposta para ele. Pode ser definido como um conjunto de etapas visando a elaboração de mudanças na realidade de uma sociedade, utilizando de mecanismos corretos para tais fins. Analisar a estrutura social como um problema público exige que seja formado a elaboração de um dado entendimento do contexto social. Somente após essa compreensão é que é possível afirmar que a situação não é a desejável, tendo como consequência a insatisfação para determinado segmento da sociedade (Lima e D’Ascenzi, 2018).

Conforme expõe Batista et al. (2021), a política pública é o principal instrumento de atuação do Estado na sociedade. Assim, ela se torna a principal ferramenta operacional do Poder Público para que seja implementada suas ações. Nesse sentido, Batista et al. (2021, p. 1) afirmam também que:

No processo de políticas, problemas são identificados, definidos e alçados à agenda governamental para solução. A formulação das intervenções pode seguir critérios de racionalidade, incrementalismo ou uma combinação de ambos. Atores políticos, burocratas, organizações da sociedade civil, grupos de interesse em diferentes níveis do governo participam desse processo que se manifesta, em seguida, nas instituições governamentais, nas quais as intervenções são decididas após barganha, acordo e convencimento. Nesse momento, alternativas são expostas e soluções eleitas. 
Sobre a formulação de políticas públicas, existem dois fatores que merecem destaque para observação, a definição da agenda e das alternativas (Capella, 2018). Enquanto a agenda trata sobre o foco sobre os problemas, as alternativas buscam identificar as soluções para as questões apresentadas. Conforme Capella (2018), existem modelos teóricos na literatura que auxiliam na compreensão sobre a forma de definição de agendas e de alternativas, destacando também entender as etapas da formulação da política pública auxilia na compreensão sobre as mudanças que podem ocorrer no processo decisório. 0 processo de elaboração de políticas públicas é executado com a participação de vários atores sociais, podendo ser pessoas ou as organizações. Conforme Howlett et al. (2013), a ação dos agentes envolvido no processo de elaboração das políticas públicas oscila conforme a etapa do ciclo.

No que tange a atuação das políticas públicas em diversas áreas de uma sociedade, pode-se destacar o campo do meio ambiente. Tendo como referência o conceito de Dye (1984), de que política pública é "o que o governo escolhe ou não fazer", a política ambiental pode ser definida como as decisões públicas relacionadas ao meio ambiente tomadas com o objetivo de atender a um equilíbrio entre as necessidades de uma sociedade e a preservação e conservação de recursos naturais. Sendo assim, uma forma de políticas públicas. Secchi (2013), ainda define a política ambiental como as decisões públicas relacionadas ao meio ambiente tomadas com o objetivo de atender um equilíbrio entre as necessidades de uma sociedade e a preservação de recursos naturais. Sendo assim, uma forma de políticas públicas. Sobre a formulação de política ambiental, Bursztyn e Bursztyn (2012, p. 182) informam:

\begin{abstract}
Ainda que, por seu caráter de política pública, as políticas ambientais sejam da responsabilidade do poder público, elas envolvem, necessariamente, outros setores da sociedade, notadamente as atividades produtivas e as associações e organizações sociais. Pelo seu caráter transversal, as políticas ambientais devem estar capilarizadas em diferentes atividades governamentais, seja como parâmetro de regulação (como é o caso da compatibilização das políticas fundiária e agrícola com os dispositivos regulamentares ambientais), seja como missão (caso da educação ambiental, de responsabilidade das escolas e universidades), ou como parcerias de diversas naturezas, envolvendo setores governamentais e não governamentais.
\end{abstract}

Os países formulam suas políticas ambientais conforme suas características, levando em consideração fatores como desenvolvimento econômico e interesses da sociedade (Bursztyn e Bursztyn, 2012). Algumas estratégias de implementação de políticas ambientais podem atuar de forma a reduzir as perdas ocasionadas por alguma iniciativa de maior escala, como uma atividade econômica. De acordo com Lima (2011), no Brasil, o alto nível de desigualdade social contrasta com a grande quantidade de recursos naturais que a nação possui. Tal situação mostra como as políticas ambientais podem atuar também como fomentadores para melhorar qualidade de vida da população.

\title{
Política ambiental no Brasil: da ótica corretiva à integradora
}

A política ambiental no Brasil desenvolveu-se de forma bastante tardia. Somente na década de 1970, a política ambiental passou a ser objeto de visibilidade aos atores políticos. Isso se deu principalmente como ato de resposta às exigências que os movimentos sociais ambientalistas exerceram através da Conferência de Estocolmo, realizada em 1972. Esse nascimento forçado, entretanto, não conseguia mostrar a fundo o desejo dos movimentos ambientalistas na preservação. A ideia de proteção ambiental parecia ser antagonista ao milagre econômico nacional, e face aos benefícios financeiros 
que viriam com o crescimento econômico, a política ambiental foi ficando em segundo plano.

Essa ideia de que o desenvolvimento econômico não poderia ser "atrapalhado" pelas questões ambientais não ficou somente nos bastidores. Em 1972, durante a conferência de Estocolmo, os países integrantes realizaram pequenos embates no campo das ideias. Parte das nações consideradas desenvolvidas, mostravam-se mais preocupados com a questão ambiental, enquanto as nações em desenvolvimento demandavam questões puramente econômicas. O Brasil encontrava-se historicamente no período conhecido como "milagre econômico brasileiro". Na visão dos governantes da época, a preocupação com as questões ambientais só tendia a prejudicar o desenvolvimento nacional, dado o alto investimento nacional em siderúrgicas, petroquímicas e energia.

Segundo Bursztyn e Bursztyn (2012, p.83), a delegação brasileira defendia pontos como:

Nos países pobres, a poluição era o subdesenvolvimento e o bem-estar era sinônimo de superação da miséria; o desenvolvimento poderia continuar de forma predatória sem que se desse prioridade para mitigar as agressões a natureza;o problema ambiental fora inventado pelas grandes potências, para conter a expansão do parque industrial dos países em desenvolvimento; a miséria seria erradicada com a difusão do crescimento econômico de acordo com a teoria do bolo: primeiro crescer para depois repartir; e a explosão demográfica não era um problema[...].

Como resultado da conferência, nasceu o documento "Declaração de Estocolmo". Segundo Bursztyn e Bursztyn 2013, este documento, apesar de não ter valor jurídico, tinha dentro de seus sete pontos e 26 princípios, um valor moral, político e operacional. Ainda Segundo Bursztyn e Bursztyn (2013), grande parte das demandas das nações em desenvolvimento foi atendida no documento. "O desenvolvimento econômico foi apontado como uma condição necessária à melhoria da qualidade de vida (Princípio 8) e as políticas ambientais nacionais não deveriam ser obstáculos à melhoria das condições de vida dos países em desenvolvimento (Princípio 11)" (Bursztyn e Bursztyn, 2013).

Entretanto a declaração resultante dessa conferência evidenciou a necessidade de concepção e implementação de algumas estratégias que pudessem gerar desenvolvimento socioeconômico equitativo congruente com meio ambiente (Bursztyn e Bursztyn, 2013).

Nesse sentido, apesar da evidente predileção da política nacional ao desenvolvimento econômico em detrimento à questão ambiental, vários dispositivos e instrumentos foram sendo criados no Brasil após a conferência de Estocolmo, como a Secretaria Especial de Meio Ambiente (SEMA) (Brasil, 1973). A criação dessa secretaria, aliada a várias outras normas já existentes à época como o Código de Águas (Brasil, 1934), Código Florestal (Brasil, 1965), Código de Proteção à Fauna (Brasil, 1967) e de Proteção à Pesca (Brasil, 1967), foram endossando o assunto e resultando na construção da política ambiental.

Para Barbieri (2007), política pública ambiental é “o conjunto de objetivos, diretrizes e instrumentos de ação que o poder público dispõe para produzir efeitos desejáveis sobre o meio ambiente".

Cabe ressaltar, porém, que nesse primeiro momento, evidencia-se a política pública ambiental sob a ótica corretiva. Atuando de modo a diminuir os impactos ambientais causados pelo desenvolvimento econômico, principal enfoque da política nacional.

No início da década de 1980, a Lei no 6.938/1981 (Brasil, 1981), estabeleceu a Política Nacional do Meio Ambiente, ao mesmo tempo em que cria o Sistema Nacional de Meio Ambiente (SISNAMA). Em sua estruturação, pode-se destacar o Conselho Nacional do 
Meio Ambiente (CONAMA), que tinha em sua composição vários atores, como representantes de ministérios e entidades setoriais da Administração Federal, diretamente envolvidos com a questão ambiental, bem como de órgãos ambientais estaduais e municipais, além de atores de entidades de classe e de organizações nãogovernamentais (Brasil, 1981).

Ao estabelecer os princípios norteadores, diretrizes e instrumentos para a política ambiental nacional, a lei trouxe como principal objetivo "a preservação ambiental propícia à vida, visando assegurar, no país, condições para o desenvolvimento socioeconômico, os interesses da segurança nacional e a proteção da dignidade da vida humana" (Brasil, 1981).

A Convenção de Viena, realizada em 1985, trouxe ao cenário internacional a necessidade de se pensar em uma nova ótica sobre a política ambiental, a ótica preventiva. Sob essa ótica, a Convenção de Viena deu enfoque à proteção da vida humana e o meio ambiente, contra os efeitos adversos possivelmente resultantes de atividades que pudessem prejudicar a camada de ozônio, como o aquecimento global, a desertificação, entre outras. A Convenção de Viena sobre a camada de ozônio foi complementada pelo Protocolo de Montreal (1987), assinado por todos os países do mundo, que se comprometeram a reduzir progressivamente a fabricação e consumo de produtos que fossem nocivos à camada de ozônio (Bursztyn e Bursztyn, 2013).

Nesse meio tempo, foram aprovados, através da Resolução CONAMA no 001/1986, os critérios básicos para a Avaliação de Impacto Ambiental (AIA) (Brasil, 1986). A implementação desse instrumento de prevenção, passou a ser utilizada como condição para realizações de projetos que pudessem impactar diretamente no meio ambiente. Essa medida acabou sendo ratificada na Constituição Federal de 1988 (Brasil, 1988), que evidenciou que essas atividades para serem realizadas, além das licenças habituais, dependeriam de licenciamento prévio do SISNAMA, além de estabelecer que:

Todos têm direito ao meio ambiente ecologicamente equilibrado, bem de uso comum do povo e essencial à sadia qualidade de vida, impondo-se ao Poder Público e à coletividade o dever de defendê-lo e preservá-lo para as presentes e futuras gerações (Brasil, 1988, art. 225).

Este momento é considerado um dos grandes marcos de mudança da ótica preventiva da política ambiental nacional. Aliados a isso, ocorre a reestruturação organizacional da política ambiental brasileira, através do Programa "Nossa Natureza", no governo do então presidente José Sarney, com a unificação de várias superintendências, criando assim o Instituto Brasileiro do Meio Ambiente e dos Recursos Naturais (IBAMA) (Brasil, 1989). Com o grande avanço tecnológico desta década e o maior enfoque ao meio ambiente e a sua preservação, a necessidade de pensar em medidas que pudessem integrar à sobrevivência humana, o desenvolvimento econômico e a conservação ambiental passaram a ser alvo de grandes estudos.

A ótica preventiva passava a ceder lugar para uma nova perspectiva, a ótica integradora. Essa visão propunha que aspectos econômicos pudessem ser integrados aos ambientais, objetivando não somente o desenvolvimento econômico sustentável, mas também a utilização racional de recursos, a fim de evitar escassez futura. Com a mudança do enfoque ambiental e a percepção da inclusão de novos temas, logo surgiu a necessidade de outra conferência a fim de gerar novos pactos e diretrizes para a política ambiental internacional, surge assim a Conferência das Nações Unidas para o Meio Ambiente e Desenvolvimento (UNCED-92), mais conhecida como Rio-92. 
A Rio-92, também conhecida como "Cúpula da Terra", buscava promulgar a concepção de desenvolvimento sustentável enfatizada desde a publicação do Relatório Brundtland (Pereira e Curi, 2012), reavivando assim a ideia de que o problema do desenvolvimento deveria ser resolvido sob uma ótica ambiental e sustentável.

A Conferência Rio'92 resultou em vários documentos que sintetizaram as preocupações dos países em relação à questão ambiental (Hogan, 2007). Entre os principais documentos, está a Agenda 21, que segundo Pott e Estrela (2017), "pode ser definida como um processo de planejamento participativo que analisa a situação atual de uma nação, um estado, uma região ou um município, e dessa forma possibilita o planejamento de um futuro sustentável".

Um dos pontos abordados pela Agenda 21 é a necessidade de alterações nas formas de consumo das pessoas, pois afirma que a produção e consumo executados de forma exacerbada estão entre as causas da degradação ambiental.

Ainda nesse sentido, Barbieri (2020) informa que a Agenda 21 definiu programas abrangendo as seguintes áreas, a) análise das formas de produção e consumo consideradas inexequíveis em longo prazo, e b) formulação de políticas nacionais de fomento a alteração desses padrões. A partir dessa conferência e a propagação da ideia de desenvolvimento sustentável como condição necessária à sobrevivência humana, surgiram várias outras concepções e conferências, como a Rio+10 e Rio+20.

De fato, a sustentabilidade econômica, tema central da Rio'92, conseguiu alcançar o objetivo de circulação da ideia. Seus desdobramentos podem ser visualizados até hoje, e viraram referências teóricas para a elaboração e implementação de políticas públicas ambientais no mundo todo.

\section{Considerações finais}

0 presente artigo teve como objetivo a revisão da literatura e dos principais conceitos utilizados para construção da política ambiental brasileira.

A construção do saber sobre o tema ambiental é de suma importância para que possam ser realizados debates e discussões acerca do tema, quando este for abordado na Agenda política, para posterior formulação da política pública. Para tanto, esse artigo passeou sobre conceitos de políticas públicas, a fim de esclarecer como o processo ocorre e como torná-lo visível aos atores políticos responsáveis por sua formulação e implementação.

Outro ponto abordado neste estudo foi a revisão do conceito de sustentabilidade. Esse conceito surgiu ainda quando as discussões sobre a temática ambiental eram percebidas através da ótica corretiva, predominante nos anos 1970. Porém, teve maior enfoque na década de 1980, quando a política ambiental começou a ter um viés preventivo, e com a ampliação do conhecimento interdisciplinar acerca do tema, o conceito foi sendo melhor definido.

Na década de 1990, já com a política ambiental sob a ótica integradora, o Desenvolvimento Sustentável passou a ser entendido como uma das principais soluções para coexistência do crescimento econômico aliado à conservação do meio ambiente. A década foi marcada por diálogos que tratavam a conservação ambiental como ponto crucial para a sobrevivência da espécie humana. Desde então, diversas políticas foram aperfeiçoadas com o intuito de promover práticas de desenvolvimento sustentável.

Apesar de todo enfoque dado, e da percepção real da necessidade de aliar desenvolvimento ao meio ambiente, o tema ainda merece mais atenção. Ao revisitar os conceitos, percebe-se a evolução do tema. Contudo, as ações ainda deixam a desejar. A grande quantidade de políticas públicas, a melhoria no aparato do estado, a inclusão de instrumentos para auxílio da proteção ambiental ainda é notória, porém, insuficiente. Entretanto é necessário entender que para além das palavras e legislações, o fator 
educacional é de suma importância para a efetivação dessas práticas. Desta forma, espera-se com este estudo, poder contribuir com este tema, através da fixação e internalização desses conceitos, tão bem conhecidos e tão pouco praticados.

\section{Conflito de interesses}

Os autores declaram não haver conflito de interesses.

\section{Referências}

Barbieri, J. C. Desenvolvimento sustentável: das origens à Agenda 2030. Petrópolis: Vozes, 2020.

Barbieri, J. C. Gestão ambiental empresarial: conceitos, modelos e instrumentos. 2. ed. São Paulo: Saraiva, 2007.

Batista, M.; Domingos, A.; Vieira, B. Políticas públicas: modelos clássicos e 40 anos de produção no Brasil. Revista Brasileira de Informação Bibliográfica em Ciências Sociais, n. 94, p. 1-25, 2021.

Boff, L. Sustentabilidade:o que é, o que não é. Petrópolis: Vozes, 2017.

Brasil. Constituição da República Federativa do Brasil de 1988. Disponível em: <http://www.planalto.gov.br/ccivil_03/constituicao/constituicao.htm>. Acesso em: 26 jun. 2021.

Brasil. Lei no 6.938, de 31 de agosto de 1981. Dispõe sobre a Política Nacional do Meio Ambiente, seus fins e mecanismos de formulação e aplicação, e dá outras providências. Disponível em: <http://www.planalto.gov.br/ccivil_03/leis/l6938.htm>. Acesso em: 18 jun. 2021.

Brasil. Decreto no 24.643, de 10 de julho de 1934. Decreta o Código de Águas. Disponível em: <http://www.planalto.gov.br/ccivil_03/decreto/d24643compilado.htm>. Acesso em: 12 jun. 2021.

Brasil. Decreto no 73.030, de 30 de outubro de 1973. Cria, no âmbito do Ministério do Interior, a Secretaria Especial do Meio Ambiente - SEMA, e da outras providências. Disponível em: <https://www2.camara.leg.br/legin/fed/decret/1970-1979/decreto73030-30-outubro-1973-421650-publicacaooriginal-1-pe.html>. Acesso em: 18 jun. 2021

Brasil. Decreto-Lei no 221, de 28 de fevereiro de 1967. Dispõe sôbre a proteção e estímulos à pesca e dá outras providências. Disponível em: <http://www.planalto.gov.br/CCIVIL_03/Decreto-Lei/Del0221compilado.htm>. Acesso em: 16 jun. 2021.

Brasil. Lei no 4.771, de 15 de setembro de 1965. Institui o novo Código Florestal. Disponível em: <http://www.planalto.gov.br/ccivil_03/leis/L4771impressao.htm>. Acesso em: 12 jun. 2021.

Brasil. Lei no 5.197, de 3 de janeiro de 1967. Dispõe sobre a proteção à fauna e dá outras providências. Disponível em: <http://www.planalto.gov.br/ccivil_03/leis/L5197 compilado.htm>. Acesso em: 16 jun. 2021.

Brasil. Lei no 6.938, de 31 de agosto de 1981. Dispõe sobre a Política Nacional do Meio Ambiente, seus fins e mecanismos de formulação e aplicação, e dá outras providências. Disponível em: <http://www.planalto.gov.br/ccivil_03/leis/l6938.htm>. Acesso em: 16 ago. 2021.

Rev. Bras. Gest. Amb. Sustent., 2021, vol. 8, n. 20, p. 1503-1513. 
Brasil. Medida Provisória no 34, de 23 de janeiro de 1989. Dispõe sobre a extinção de órgão e de entidade autárquica, cria o Instituto Brasileiro do Meio Ambiente e dos Recursos Naturais Renováveis e dá outras providências. Disponível em: <http://www.planalto.gov.br/ccivil_03/MPV/1988-1989/034.htm>. Acesso em: 16 ago. 2021.

Brasil. Resolução CONAMA no 001, de 23 de janeiro de 1986. Disponível em: <http://conama.mma.gov.br/?option=com_sisconama\&task=arquivo.download\&id=745>. Acesso em: 18 jun. 2021.

Bursztyn, M.; Bursztyn, M. A. Fundamentos de política e gestão ambiental: os caminhos do desenvolvimento. Rio de Janeiro: Garamond, 2012.

Capella, A. C. N. Formulação de políticas públicas. Brasília: ENAP, 2018.

Dye, T. Understanding public policy. Englewood Cliffs, New Jersey: Prentice Hall, 1984.

Hogan, D. J. População e meio ambiente: a emergência de um novo campo de estudos. In: Hogan, D. J. (Org.). Dinâmica populacional e mudança ambiental: cenários para o desenvolvimento brasileiro. Campinas: Núcleo de Estudos de População, 2007. p. 13-49.

Howlett, M.; Ramesh, M.; Perl, A. Política pública, seus ciclos e subsistemas: uma abordagem integral. Rio de Janeiro: Elsevier, 2013.

Lavieille, J.-M. Driot international de l'environnement. 2. ed. Paris: Ellipses, 2004.

Liczbinski, C. R. M. Meio ambiente e consumo sustentável: o papel do Código de Defesa do Consumidor na concretização da cidadania. 2. ed. Curitiba: APPRIS, 2021.

Lima, G. F. C. A institucionalização das políticas públicas e da gestão ambiental o Brasil: avanços, obstáculos e contradições. Desenvolvimento e Meio Ambiente, n. 23, p. 121-132, 2015. http://dx.doi.org/10.5380/dma.v23i0.20948

Lima, L. L.; D’Ascenzi, L. L. Políticas públicas, gestão urbana e desenvolvimento local. Porto Alegre: Metamorfose, 2018.

Magrini, A. Política e gestão ambiental: conceitos e instrumentos. Revista Brasileira de Energia, v. 8, n. 2, p. 1-8, 2001.

Pereira, S. S.; Curi, R. C. Meio ambiente, impacto ambiental e desenvolvimento sustentável: conceituações teóricas sobre o despertar da consciência ambiental. REUNIR - Revista de Administração Contabilidade e Sustentabilidade, v. 2, n. 4, p. 35-57, 2012. https://doi.org/10.18696/reunir.v2i4.78

Pott, C. M.; Estrela, C. C. Histórico ambiental: desastres ambientais e o despertar de um novo pensamento. Estudos Avançados, v. 31, n. 89, p. 271-283, 2017. https://doi.org/10.1590/s0103-40142017.31890021

Secchi, L. Políticas públicas: conceitos, esquemas de análises e casos práticos. 2. ed. São Paulo: CENAGE, 2013.

Seiffert, M. E. B. Gestão ambiental: instrumentos, esferas de ação e educação ambiental. 1. ed. São Paulo: Atlas, 2007. 
Silva, A. L. M. Direito do meio ambiente e dos recursos naturais: Volume I: Impacto ambiental. PNMA. SISNAMA. Licenciamento Ambiental. Responsabilidade Ambiental. Rio de Janeiro: O Autor, 2015.

Souza, C. Coordenação de políticas públicas. Brasília: ENAP, 2018.

CC Informação da Licença: Este é um artigo Open Access distribuído sob os termos da Licença Creative Commons Attribution, que permite uso irrestrito, distribuição e reprodução em qualquer meio, desde que a obra original seja devidamente citada. 